\title{
Vasopressors in septic shock: a systematic review and network meta-analysis
}

\author{
This article was published in the following Dove Press journal: \\ Therapeutics and Clinical Risk Management \\ 14 July 2015 \\ Number of times this article has been viewed
}

\author{
Feihu Zhou ${ }^{1, *}$ \\ Zhi Mao',* \\ Xiantao Zeng',* \\ Hongjun Kang' \\ Hui Liu' \\ Liang Pan' \\ Peter $\mathrm{C} \mathrm{Hou}{ }^{3}$ \\ 'Department of Critical Care \\ Medicine, Chinese People's Liberation \\ Army General Hospital, Beijing, \\ ${ }^{2}$ Center for Evidence-Based and \\ Translational Medicine, Zhongnan \\ Hospital, Wuhan University, \\ Wuhan, People's Republic of China; \\ ${ }^{3}$ Department of Emergency Medicine, \\ Brigham and Women's Hospital, \\ Harvard Medical School, Boston, MA, \\ USA \\ *These authors contributed equally \\ to the paper
}

Correspondence: Feihu Zhou Department of Critical Care Medicine, Chinese People's Liberation Army General Hospital, 28 Fu-Xing Road, Beijing 100853, People's Republic of China

Tel +861066938148

Fax +861088219862

Email zhoufh30I@I26.com
Objective: Vasopressor agents are often prescribed in septic shock. However, their effects remain controversial. We conducted a systematic review and Bayesian network meta-analysis to compare the effects among different types of vasopressor agents.

Data sources: We searched for relevant studies in PubMed, Embase, and the Cochrane Library databases from database inception until December 2014.

Study selection: Randomized controlled trials in adults with septic shock that evaluated different vasopressor agents were selected.

Data extraction: Two authors independently selected studies and extracted data on study characteristics, methods, and outcomes.

Data synthesis: Twenty-one trials $(n=3,819)$ met inclusion criteria, which compared eleven vasopressor agents or vasopressor combinations (norepinephrine [NE], dopamine [DA], vasopressin [VP], epinephrine [EN], terlipressin [TP], phenylephrine [PE], TP+NE, TP + dobutamine [DB], NE+DB, NE+EN, and NE + dopexamine [DX]). Except for the superiority of NE over DA, the mortality of patients treated with any vasopressor agent or vasopressor combination was not significantly different. Compared to DA, NE was found to be associated with decreased cardiac adverse events, heart rate (standardized mean difference [SMD]: -2.10 ; 95\% confidence interval $[\mathrm{CI}]:-3.95,-0.25 ; P=0.03$ ), and cardiac index (SMD: $-0.73 ; 95 \%$ CI: $-1.14,-0.03 ; P=0.004)$ and increased systemic vascular resistance index (SVRI) (SMD: 1.03; 95\% CI: 0.61, 1.45; $P<0.0001)$. This Bayesian meta-analysis revealed a possible rank of probability of mortality among the eleven vasopressor agents or vasopressor combinations; from lowest to highest, they are NE+DB, EN, TP, NE+EN, TP+NE, VP, TP+DB, NE, PE, $\mathrm{NE}+\mathrm{DX}$, and DA.

Conclusion: In terms of survival, NE may be superior to DA. Otherwise, there is insufficient evidence to suggest that any other vasopressor agent or vasopressor combination is superior to another. When compared to DA, NE is associated with decreased heart rate, cardiac index, and cardiovascular adverse events, as well as increased SVRI. The effects of vasopressor agents or vasopressor combinations on mortality in patients with septic shock require further investigation

Keywords: norepinephrine, dopamine, vasopressors, sepsis, shock, network meta-analysis

\section{Introduction}

Septic shock is a life-threatening condition and severe sepsis accounts for $20 \%$ of all admissions to intensive care units. ${ }^{1}$ Severe sepsis approximates 750,000 cases annually in the USA and has a mortality rate averaging $28 \% .{ }^{2}$ For initial resuscitation, intravenous fluids are recommended as the first-line therapy. However, vasopressor agents are also critical to achieve and maintain adequate blood pressure and tissue perfusion, and hence, should be used early. ${ }^{3} \mathrm{Sakr}$ et $\mathrm{al}^{4}$ reported that the most frequently used vasopressor agent during septic shock was norepinephrine (NE, 80.2\%), 
followed by dopamine (DA, 35.4\%), and epinephrine (EN, $23.3 \%$ ) alone or in combination. Although NE is recommended as the fist-line agent for treating hypotension in volume-resuscitated hyperdynamic septic shock, ${ }^{5}$ the second-line vasopressor remains controversial. Previous studies have reported that NE may have significant superiority over DA in terms of survival. ${ }^{5-8}$ However, compared with other vasopressors, such as EN, vasopressin (VP), terlipressin (TP), and phenylephrine (PE), the outcomes on the use of NE were not different. Morelli et $\mathrm{al}^{9}$ reported that there was no difference in terms of cardiopulmonary performance, global oxygen transport, and regional hemodynamics when PE was administered instead of NE in the initial hemodynamic support of septic shock. Russell et al ${ }^{10}$ revealed that low-dose VP did not improve survival rates in contrast with NE in septic shock patients treated with catecholamine vasopressors. Additionally, EN was recommended as an additional agent to NE to maintain adequate blood pressure. ${ }^{5}$ Recently in a single-center randomized controlled trial (RCT), NE supplemented by dobutamine (DB) was compared to NE supplemented by EN in the treatment of septic shock patients. ${ }^{11}$ However, the effectiveness of other vasopressor agents or vasopressor combinations as compared to others is limited. Whether the use of any vasopressor agents or vasopressor combinations in patients with septic shock translates to a survival advantage remains unclear. Meta-analyses of vasopressor agents have been limited by considering only two or three categories of vasopressor agents, not including indirect and direct comparisons, and omission of recent RCTs. Therefore, we performed a network meta-analysis (NMA) considering direct and indirect comparisons of vasopressor agents and vasopressor combinations in reducing overall mortality for septic shock patients.

\section{Materials and methods}

The Preferred Reporting Items for Systematic Reviews and Meta-Analyses (PRISMA Statement) guidelines were used to perform this meta-analysis. ${ }^{12}$

\section{Information sources and eligibility criteria} A search of the PubMed (US National Library of Medicine, Bethesda, MD, USA) and Cochrane Library databases and Embase from database inception to December 2014 was performed. The eligibility criteria were as follows: the study design must be randomized controlled, the study must report mortality outcome, and the study must evaluate adult patients at least 18 years of age.

\section{Search strategy}

We used text words and medical subject heading (MeSH) terms with Boolean strategy. The cross-searching was done based on the following three categories: 1) vasopressors related ("vasopressor" or "vasoactive drug" or "catecholamine" or "pressor agent"); 2) different vasopressors ("norepinephrine" or "dopamine" or "epinephrine" or "adrenaline" or "isuprel" or "aleudrin" or "vasopressin" or "terlipressin" or "phenylephrine" or "dopexamine"); 3) disease ("sepsis" or "infection" or "septic shock" or "shock" or "systemic inflammatory response syndrome" or "SIRS"). The search was limited to the "English" language and "human" subjects. Further search by reviewing conference proceedings and the references of review articles was performed manually if necessary.

\section{Study selection}

Two independent investigators (FZ and ZM) performed the study selection. Differences between the two investigators were resolved by consensus or adjudicated by a third investigator (XZ). Agreement between the two reviewers on study inclusion was excellent $(k=1)$. Studies on adult patients with septic shock that evaluated the mortality rates of different vasopressor agents or vasopressor combinations were selected.

\section{Data extraction}

Two investigators independently extracted raw data using a standard form for each study. The form included year of publication, the study type, number of patients, patient characteristics, and details of the outcomes. The main outcome was 28-day mortality. We used the mortality rate from the only undetermined time point or the nearest time point when mortality was reported at only an undetermined time point or several time points, respectively. In addition, we also assessed cardiac adverse events and hemodynamic and metabolic parameters.

\section{Quality assessment}

We assessed the quality of each study selected for this meta-analysis by using the Jadad score, which includes the following criteria: randomization, concealment of treatment allocation, clinician blinding, baseline balance between groups, and the description of withdrawals and dropouts. ${ }^{13}$

\section{Statistical analysis}

A meta-analysis was performed to calculate direct estimates of treatment effect for each pair of vasopressor agents or 
vasopressor combinations. According to heterogeneity of treatment effect across trials using the $I^{2}$-statistics, ${ }^{14}$ a fixedeffect model $(P \geq 0.1)$ or random-effects model $(P<0.1)$ was used. Results in terms of odds ratio (OR) for dichotomous outcomes or standardized mean difference (SMD) for continuous data were expressed with mean and $95 \%$ confidence intervals (CIs). The direct meta-analysis was done using Review Manager, version 5.1.2 (RevMan; The Cochrane Collaboration, Oxford, UK).

Using a Bayesian framework, we performed randomeffects NMAs for each vasopressor agent or vasopressor combination. NMA is a recent emerging approach used to evaluate the effect size of all possible pairwise comparisons even if they are not compared head-to-head. ${ }^{15}$ Results such as ORs are expressed with 95\% CIs. These CIs from NMAs are the Bayesian analogs of the $95 \%$ CIs. ${ }^{15}$ The models had 80,000 iterations, while a burn-in of 40,000 and a thin of 10 were used. ${ }^{16}$ Vague priors were used. ${ }^{16}$ All convergence on the basis of Brooks-Gelman-Rubin plots was assessed. ${ }^{16}$ Cumulative probability plot (cumulative probability vs rank curve) is presented. Using R-project 3.1.1, the $Z$-test was conducted to assess for inconsistency of triangular loops. ${ }^{17}$ Area under the cumulative probability curve represents the rank of probability. The analysis for the NMA was performed using WinBUGS1.4.3 (Medical Research Council Biostatistics Unit; www.mrc-bsu.cam. ac.uk/software/bugs/) and R-project 3.1 .1 (http://cran.rproject.org/). Publication bias was tested by funnel plots whenever possible.

\section{Results Study selection}

There were 4,280 potentially relevant studies, and 49 articles were retrieved for detailed assessment. Twenty-eight articles were excluded because there were no mortality comparisons $(n=20)$, no sepsis patients $(n=2)$, other septic shock investigations $(n=3)$, and post hoc analyses $(n=3)$. Twenty-one studies were included in this meta-analysis (Figure 1). ${ }^{9-11,18-35}$ To evaluate hemodynamic outcomes, we extracted heart rate (HR), mean arterial pressure (MAP), systemic vascular
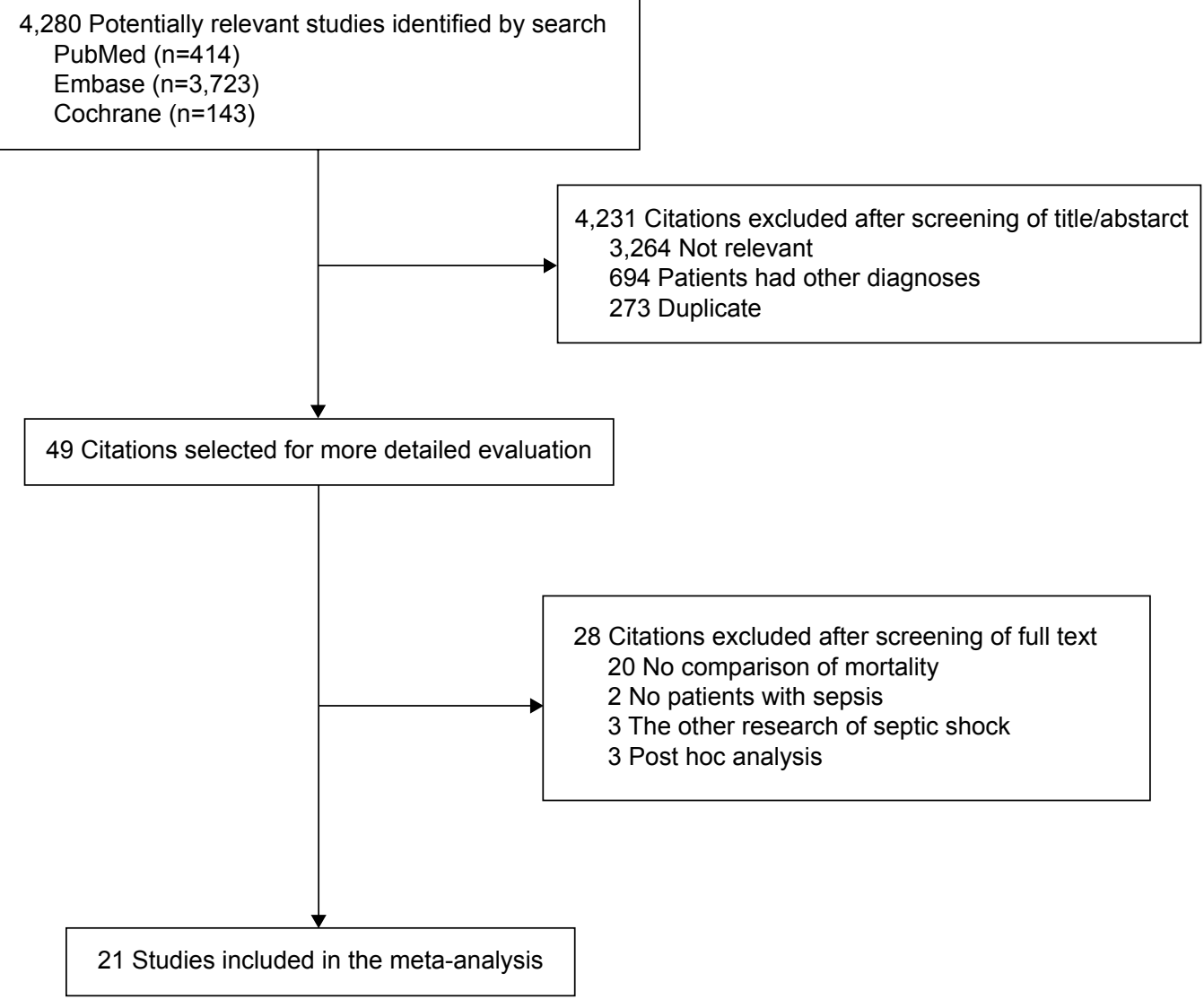

Figure I Quorum chart of study cohort.

Note: The search had been conducted using the PubMed, Embase, and the Cochrane Library databases from database inception to December 2014. 
resistance index (SVRI), cardiac index, and mortality data from studies by Russell et $\mathrm{al}^{10}$ and Gordon et al. ${ }^{30}$

\section{Study characteristics}

Fourteen single-center ${ }^{9,11,18-24,26,29,31,32,34}$ and seven multicenter studies ${ }^{10,25,27,28,30,33,35}$ were identified. The characteristics and inclusion criteria of the selected RCTs are summarized in Table 1. These articles were reported between 1993 and 2012, and a total of 3,819 patients were included in this study. Inclusion criteria were not the same for all trials; however, all patients met the diagnosis of severe sepsis or septic shock (Table 1). ${ }^{36}$ Mean age ranged from 18 years to 70 years, and the proportion of male patients ranged from $46 \%$ to $77.3 \%$. The mean Acute Physiology and Chronic Health Evaluation II (APACHE II) score was 23.8.

All studies evaluated the vasopressor effects in patients with septic shock by using a primary outcome such as survival, hemodynamics, or APACHE II score (Table 2). Vasopressor agents include NE, 9,10,18-20,23,25,26,28-35 $\mathrm{EN},{ }^{21,22,24,27,28} \mathrm{VP},{ }^{10,25,30,31,33} \mathrm{DA},{ }^{18-20,26,34,35} \mathrm{TP},{ }^{23,31} \mathrm{PE},{ }^{9,32}$ $\mathrm{NE}+\mathrm{DB},{ }^{11,21,22} \mathrm{NE}+\mathrm{EN},{ }^{11} \mathrm{TP}+\mathrm{NE},{ }^{9} \mathrm{TP}+\mathrm{DB},{ }^{9}$ and $\mathrm{NE}+$ dopexamine (DX) (Table 2, Figure 2). ${ }^{24}$ The mortality data from the RCT by De Backer et $\mathrm{al}^{7,35}$ were extracted from their meta-analysis.

\section{Risk of bias within studies}

Only RCTs were included in the analysis. Sequence of randomized allocation was reported in all but two studies. ${ }^{22,34}$ Blinding was conducted in nine studies. ${ }^{9-11,20,27,30,32,33,35}$ The mean Jadad score was 3.3.

\section{Effect of different vasopressor agents on mortality}

Mortality in these 21 trials was 50.1\% (1,915/3,819). When compared to NE, DA was associated with increased mortality (OR: 1.24, 95\% CI: 1.01, 1.53). However, there was no significant difference in mortality in direct or indirect comparisons between other different vasopressor agents and vasopressor combinations $(P>0.05)$ (Figure 3$)$. For the probability of mortality, the possible rank from low to high was $\mathrm{NE}+\mathrm{DB}$ (area under the curve [AUC]: 0.2648), EN (AUC: 0.3473), TP (AUC: 0.379), NE+EN (AUC: 0.3943), TP+NE (AUC: 0.3967), VP (AUC: 0.4212), TP+DB (AUC: 0.5423), NE (AUC: 0.5752), PE (AUC: 0.6796), NE+DX (AUC: 0.7279), and DA (AUC: 0.7718) (Figures 4 and 5). The tests of inconsistency for the two triangular closed loops were not significant (Figure 6). This meant that direct and indirect estimates had similar effects in the closed loop. ${ }^{15,17}$

\section{Effect of different vasopressor agents on cardiac adverse events}

Included studies compared NE vs DA, NE vs VP, NE vs TP, $\mathrm{NE}$ vs $\mathrm{PE}, \mathrm{TP}+\mathrm{NE}$ vs TP+DB, and TP+DB vs EN directly. We performed direct meta-analysis of cardiac adverse events, which mainly consisted of arrhythmias and tachycardia. NE decreased cardiac adverse events significantly compared to DA (Table 3). No significant difference in cardiac adverse events was found between other vasopressor agents and vasopressor combinations.

\section{Effect of different vasopressors on hemodynamic and metabolic parameters}

Thirteen studies reported that there were significant differences in the effect on hemodynamics, ${ }^{10,11,18,20,22-26,29-32}$ and eleven studies reported that there were significant differences on metabolic parameters or organ function between vasopressor agents and vasopressor combinations (Table 2). ${ }^{11,18-22,24-26,29,31,33}$

Four trials with complete data compared the treatment of NE and DA. ${ }^{18-20,26}$ The results revealed that NE decreased HR (SMD: $-2.10 ; 95 \% \mathrm{CI}:-3.95,-0.25 ; P=0.03$ ) and cardiac index (SMD: $-0.73 ; 95 \% \mathrm{CI}:-1.14,-0.03 ; P=0.004)$ and increased SVRI (SMD: 1.03; 95\% CI: 0.61, 1.45; $P<0.0001$ ), but there was no significant difference on MAP, oxygen delivery $\left(\mathrm{DO}_{2}\right)$, oxygen consumption $\left(\mathrm{VO}_{2}\right)$, and lactate. In contrast, as compared to NE, VP significantly decreased HR (SMD: 0.21; 95\% CI: 0.07, 0.34; $P=0.003$ ).

Compared to the NE+DB combination, EN did not show a significant difference in HR, MAP, cardiac index, pulmonary MAP, $\mathrm{DO}_{2}, \mathrm{VO}_{2}$, and lactate (Table 4). However, the $\mathrm{NE}+\mathrm{EN}$ combination was more effective than the NE+DB combination in reversing the abnormalities of cardiovascular parameters, and the NE+EN group had significantly higher MAP, HR, CVP, cardiac index, SVRI, ejection fraction, left ventricular end diastolic volume, $\mathrm{DO}_{2}$, lactate, and urine output. $^{11}$

\section{Discussion}

Twenty-one trials that included 3,819 patients and that compared different vasopressor agents or vasopressor combinations in septic shock were identified and included in this systematic review and NMA of RCTs. The trials' mean Jadad score was 3.3, which means that they were of high quality. The main results showed that except for the superiority of NE over DA in direct comparison, the mortality of patients treated with any other vasopressor agent or vasopressor combination was not significantly different. 


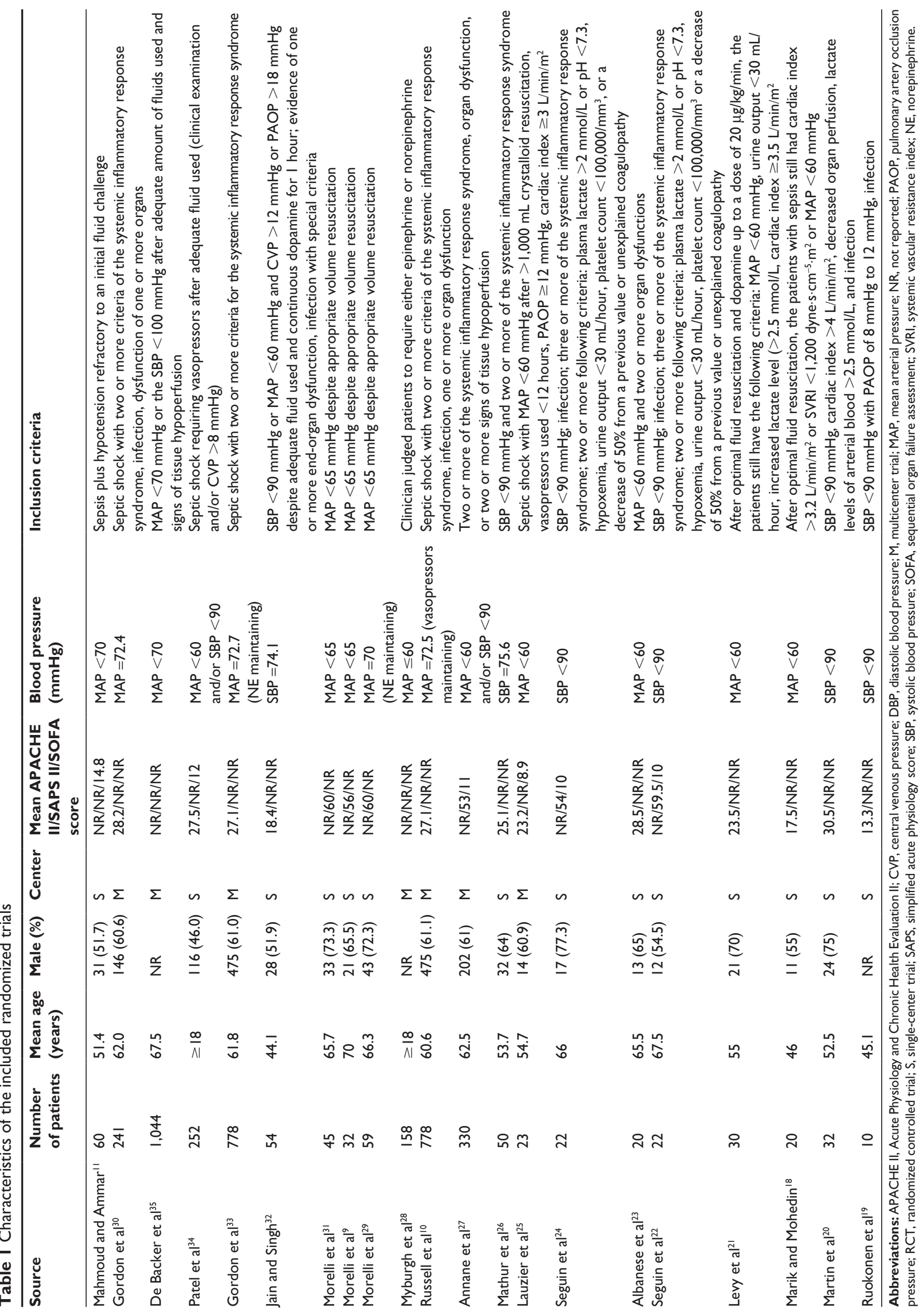




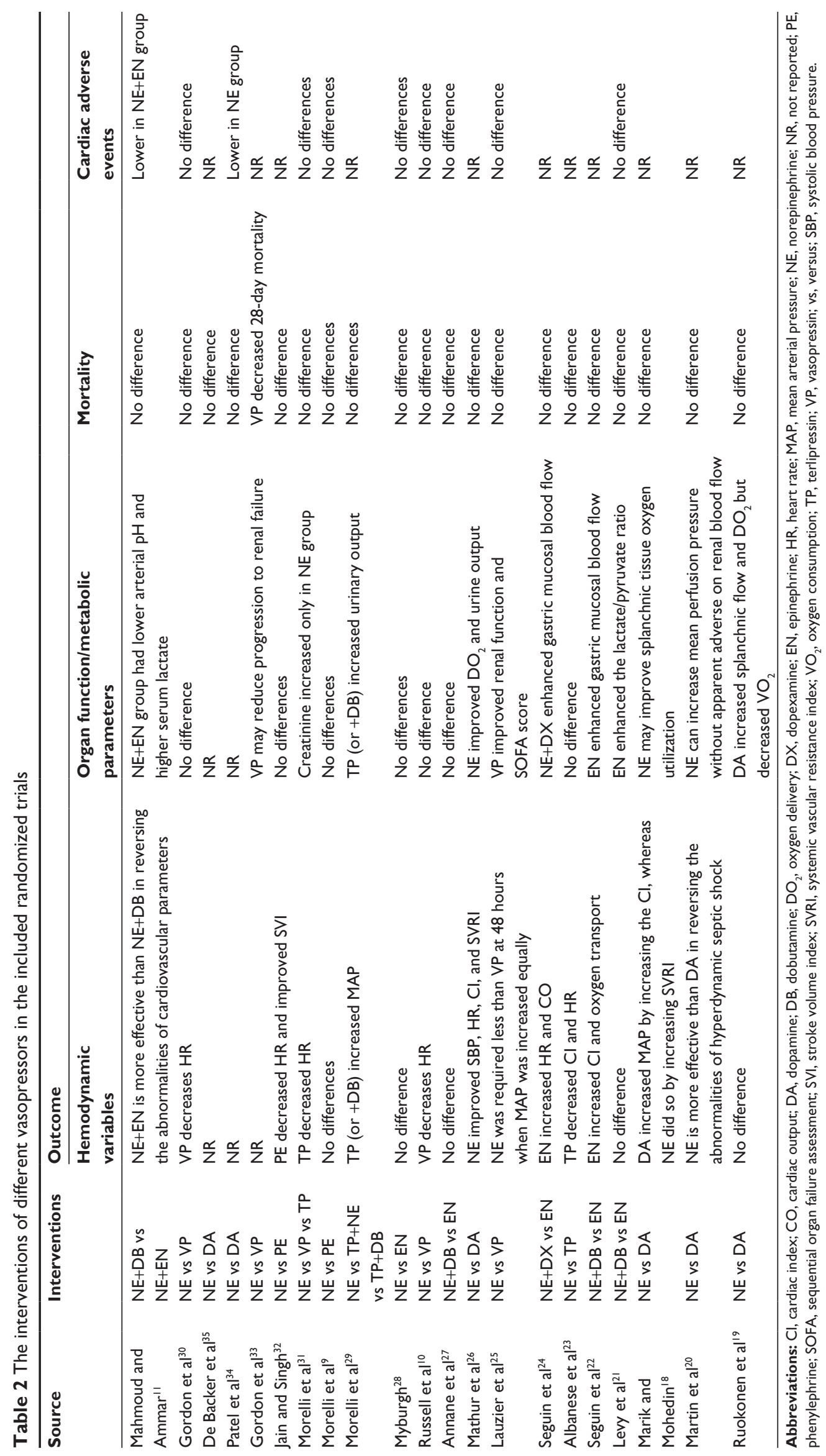




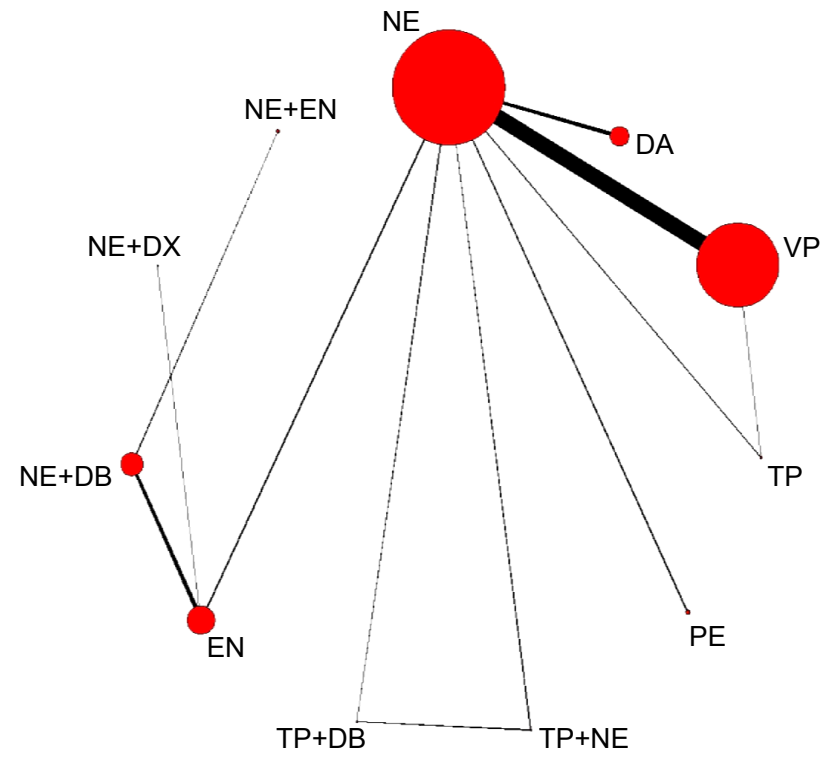

Figure 2 Network of eligible comparisons for the multiple-treatment meta-analysis for mortality.

Notes: The width of the lines is proportional to the number of trials comparing each pair of treatments, and the size of each node is proportional to the number of randomized participants (sample size). The network of eligible comparisons for acceptability (dropout rate) analysis is similar.

Abbreviations: DA, dopamine; DB, dobutamine; DX, dopexamine; EN, epinephrine; $\mathrm{NE}$, norepinephrine; PE, phenylephrine; TP, terlipressin; VP, vasopressin.

NE was also associated with decreased cardiac adverse events, HR, and cardiac index, as well as increased SVRI, as compared to DA.

Our meta-analysis revealed a possible rank of probability of mortality among the eleven vasopressor agents or vasopressor combination; from low to high, they are
$\mathrm{NE}+\mathrm{DB}, \mathrm{EN}, \mathrm{TP}, \mathrm{NE}+\mathrm{EN}, \mathrm{TP}+\mathrm{NE}, \mathrm{VP}, \mathrm{TP}+\mathrm{DB}, \mathrm{NE}, \mathrm{PE}$, $\mathrm{NE}+\mathrm{DX}$, and DA. However, variations in each RCT's inclusion criteria may have influenced the probability of mortality. Thus, this ranking should be interpreted with caution.

Our NMA evaluated the vasopressor agents or vasopressor combinations from both direct and indirect comparisons. This approach differs from traditional head-to-head metaanalysis. Some traditional meta-analyses of RCTs have compared only two or three vasopressor agents, such as NE, DA, and VP. ${ }^{10,35}$ However, other types of comparisons have never been performed. This NMA compared any vasopressor agent or vasopressor combination to others and revealed a possible rank of probability of mortality. ${ }^{15}$

Three factors support the internal validity of our analysis. First, a rigorous and extensive literature search was conducted, and the number of selected studies was more than any in previous meta-analyses focusing on vasopressor agents and vasopressor combinations for the treatment of septic shock. Second, the selected trials are considered high-quality studies, with a mean Jadad score of 3.3 points. Third, tests of inconsistency for triangular loops were not significant; in other words, the direct and indirect estimates had similar effects. This finding supports that our NMA has adequate homogeneity, which translates to more confidence in support of the results.

Vasopressor therapy is recommended by every major clinical practice guideline when fluid resuscitation fails

\begin{tabular}{|c|c|c|c|c|c|c|c|c|c|c|}
\hline $\mathrm{NE}$ & $\begin{array}{c}1.24 \\
(1.01,1.53)\end{array}$ & $\begin{array}{c}0.91 \\
(0.75,1.11)\end{array}$ & $\begin{array}{c}0.73 \\
(0.24)\end{array}$ & $\begin{array}{c}1.21 \\
(0.51,2.86)\end{array}$ & $\begin{array}{c}0.73 \\
(0.19,2.79)\end{array}$ & $\begin{array}{c}1.00 \\
(0.26,3.87)\end{array}$ & $\begin{array}{c}0.70 \\
(0.34,1.43)\end{array}$ & - & - & - \\
\hline $\begin{array}{c}1.3 \\
(0.96,1.84)\end{array}$ & DA & - & - & - & - & - & - & - & - & - \\
\hline $\begin{array}{c}0.86 \\
(0.61,1.16)\end{array}$ & $\begin{array}{c}0.68 \\
(0.4,1.003)\end{array}$ & VP & $\begin{array}{c}0.77 \\
(0.18)\end{array}$ & - & - & - & - & - & - & - \\
\hline $\begin{array}{c}0.85 \\
(0.25,2.12)\end{array}$ & $\begin{array}{c}0.67 \\
(0.19,1.71)\end{array}$ & $\begin{array}{c}1.003 \\
(0.3,2.53)\end{array}$ & TP & - & - & - & - & - & - & - \\
\hline $\begin{array}{c}1.36 \\
(0.48,3.03)\end{array}$ & $\begin{array}{c}1.08 \\
(0.34,2.51)\end{array}$ & $\begin{array}{c}1.63 \\
(0.53,3.77)\end{array}$ & $\begin{array}{c}2.16 \\
(0.4,6.998)\end{array}$ & PE & - & - & - & - & - & - \\
\hline $\begin{array}{c}0.98 \\
(0.17,3.29)\end{array}$ & $\begin{array}{c}0.77 \\
(0.13,2.66)\end{array}$ & $\begin{array}{c}1.17 \\
(0.19,3.93)\end{array}$ & $\begin{array}{c}1.55 \\
(0.17,5.803)\end{array}$ & $\begin{array}{c}0.89 \\
(0.11,3.43)\end{array}$ & $\mathrm{TP}+\mathrm{NE}$ & $\begin{array}{c}1.36 \\
(0.36,5.17)\end{array}$ & - & - & - & - \\
\hline $\begin{array}{c}1.31 \\
(0.23,4.18)\end{array}$ & $\begin{array}{c}1.03 \\
(0.17,3.48)\end{array}$ & $\begin{array}{c}1.56 \\
(0.26,5.08)\end{array}$ & $\begin{array}{c}2.03 \\
(0.23,7.86)\end{array}$ & $\begin{array}{c}1.2 \\
(0.15,4.86)\end{array}$ & $\begin{array}{c}1.76 \\
(0.32,5.66)\end{array}$ & $\mathrm{TP}+\mathrm{DB}$ & - & - & - & - \\
\hline $\begin{array}{c}0.77 \\
(0.31,1.62)\end{array}$ & $\begin{array}{c}0.61 \\
(0.22,1.33)\end{array}$ & $\begin{array}{c}0.92 \\
(0.34,1.99)\end{array}$ & $\begin{array}{c}1.22 \\
(0.25,3.53)\end{array}$ & $\begin{array}{c}0.71 \\
(0.17,2.02)\end{array}$ & $\begin{array}{c}1.38 \\
(0.18,4.98)\end{array}$ & $\begin{array}{c}1.04 \\
(0.14,4.04)\end{array}$ & EN & $\begin{array}{c}0.86 \\
(0.57,1.30)\end{array}$ & $\begin{array}{c}2.14 \\
(0.28,16.37)\end{array}$ & - \\
\hline $\begin{array}{c}0.71 \\
(0.24,1.71)\end{array}$ & $\begin{array}{c}0.56 \\
(0.17,1.36)\end{array}$ & $\begin{array}{c}0.84 \\
(0.27,2.11)\end{array}$ & $\begin{array}{c}1.11 \\
(0.21,3.45)\end{array}$ & $\begin{array}{c}0.65 \\
(0.14,1.99)\end{array}$ & $\begin{array}{c}1.27 \\
(0.15,4.86)\end{array}$ & $\begin{array}{c}0.96 \\
(0.11,3.81)\end{array}$ & $\begin{array}{c}0.91 \\
(0.54,1.501)\end{array}$ & $\mathrm{NE}+\mathrm{DB}$ & - & $\begin{array}{c}1.14 \\
(0.41,3.15)\end{array}$ \\
\hline $\begin{array}{c}4.95 \\
(0.19,24.21)\end{array}$ & $\begin{array}{c}3.95 \\
(0.14,18.85)\end{array}$ & $\begin{array}{c}5.92 \\
(0.22,28.96)\end{array}$ & $\begin{array}{c}8.04 \\
(0.18,40.1)\end{array}$ & $\begin{array}{c}4.38 \\
(0.13,23.88)\end{array}$ & $\begin{array}{c}9.52 \\
(0.16,55.39)\end{array}$ & $\begin{array}{c}7.23 \\
(0.13,39.79)\end{array}$ & $\begin{array}{c}6.62 \\
(0.3,29.21)\end{array}$ & $\begin{array}{c}7.57 \\
(0.32,36.73)\end{array}$ & $\mathrm{NE}+\mathrm{DX}$ & - \\
\hline $\begin{array}{c}0.95 \\
(0.18,3.09)\end{array}$ & $\begin{array}{c}0.74 \\
(0.13,2.45)\end{array}$ & $\begin{array}{c}1.14 \\
(0.21,3.82)\end{array}$ & $\begin{array}{c}1.5 \\
(0.17,5.82)\end{array}$ & $\begin{array}{c}0.87 \\
(0.11,3.39)\end{array}$ & $\begin{array}{c}1.72 \\
(0.13,7.78)\end{array}$ & $\begin{array}{c}1.28 \\
(0.1,5.78)\end{array}$ & $\begin{array}{c}1.24 \\
(0.33,3.32)\end{array}$ & $\begin{array}{c}1.36 \\
(0.41,3.35)\end{array}$ & $\begin{array}{c}0.87 \\
(0.03,4.77)\end{array}$ & $\mathrm{NE}+\mathrm{EN}$ \\
\hline
\end{tabular}

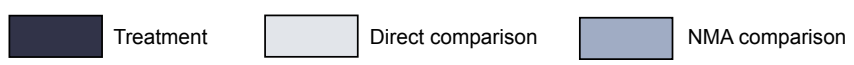

Figure 3 Mortality of different vasopressors in direct comparison and network meta-analysis in terms of mortality.

Notes: Results are the ORs and Cls in the row-defining treatment compared with the ORs and Cls in the column-defining treatment. For mortality, ORs $>$ I favor the rowdefining treatment. Network meta-analysis results are at the bottom-left of the figure, while direct comparison results are at the upper-right of the figure.

Abbreviations: $\mathrm{Cl}$, confidence interval; DA, dopamine; DB, dobutamine; DX, dopexamine; EN, epinephrine; NE, norepinephrine; NMA, network meta-analysis; OR, odds ratio; PE, phenylephrine; TP, terlipressin; VP, vasopressin. 


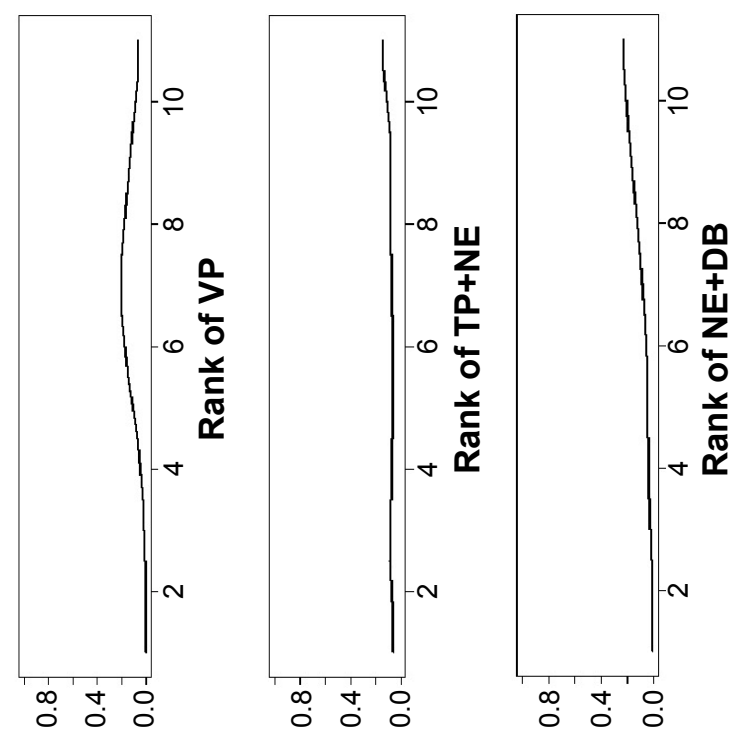

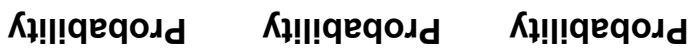
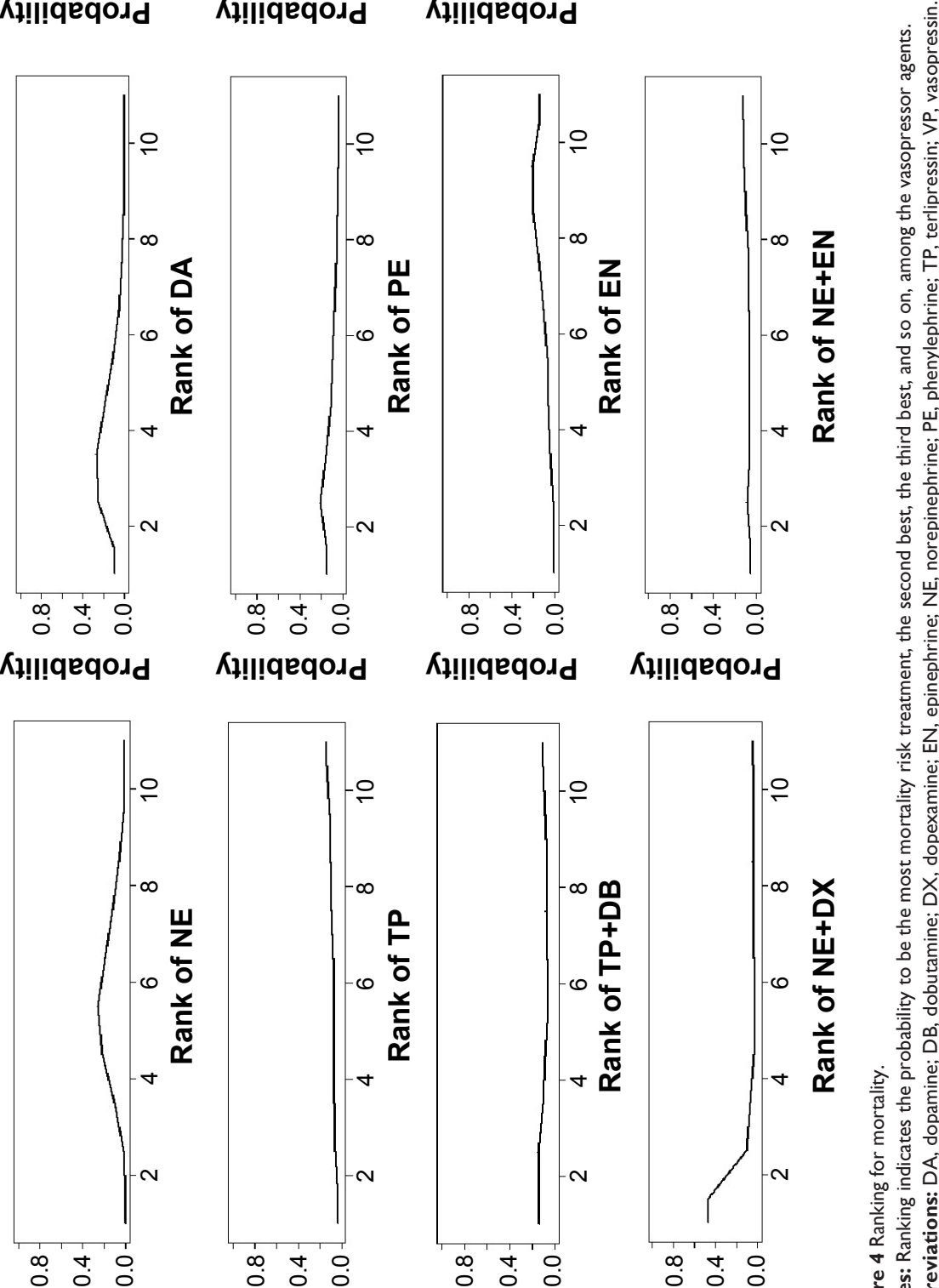

ᄉł!!!qeqo.dd

К‼!quqodd
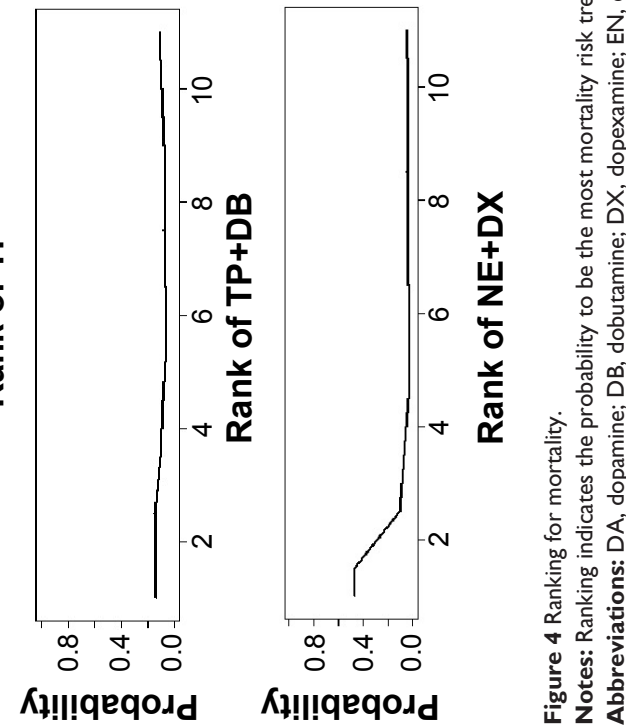

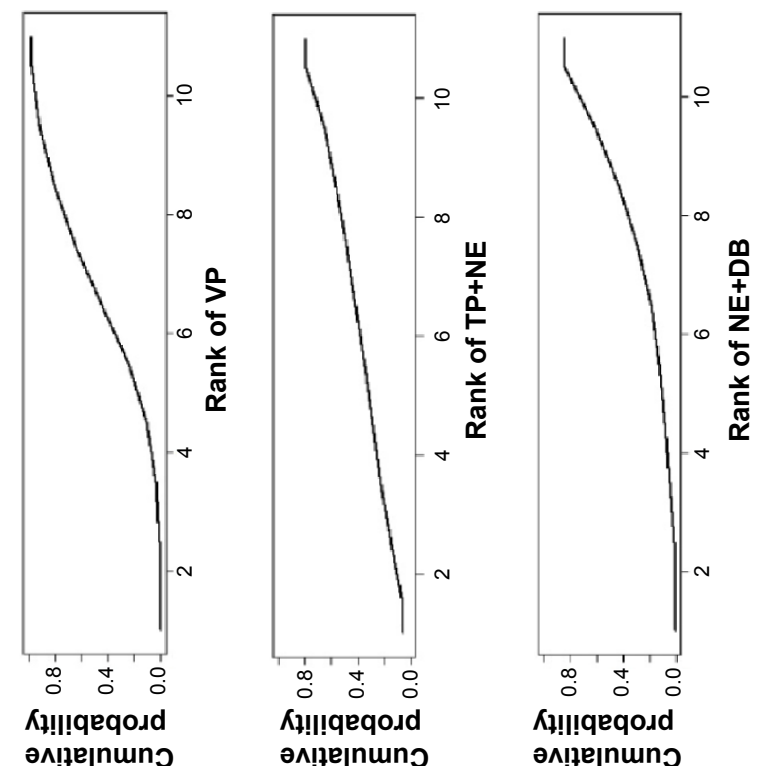

$\Lambda_{1 ! ! ! q e q o u d}$

әм!ฺำuñ

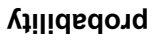

әм!̣e|numว
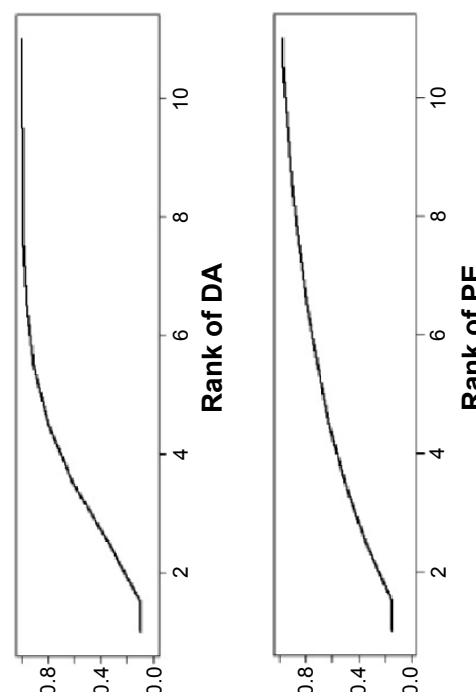

ᄉ 1 !!!qeqoud

әм!̣ejnun?

Kł!!!qeqoıd

әм!̣eןnumo
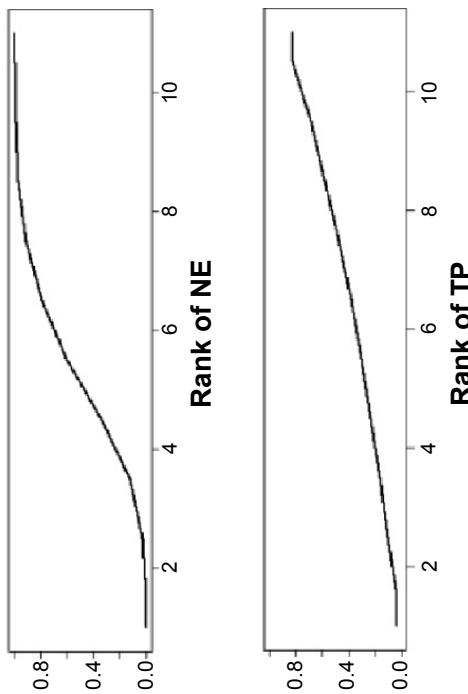

К‼!qqeqoud

әм!ฺए!nunว

Kt!!!qeqo,d

әм!̣eןnunว

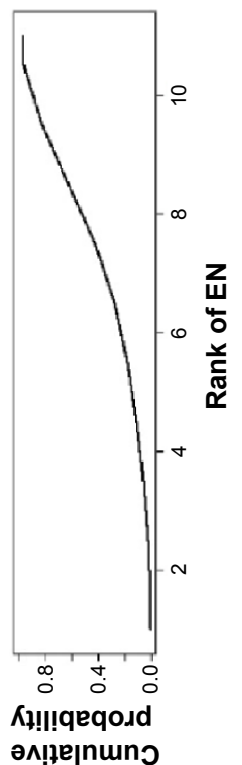

әм!łeןnunว
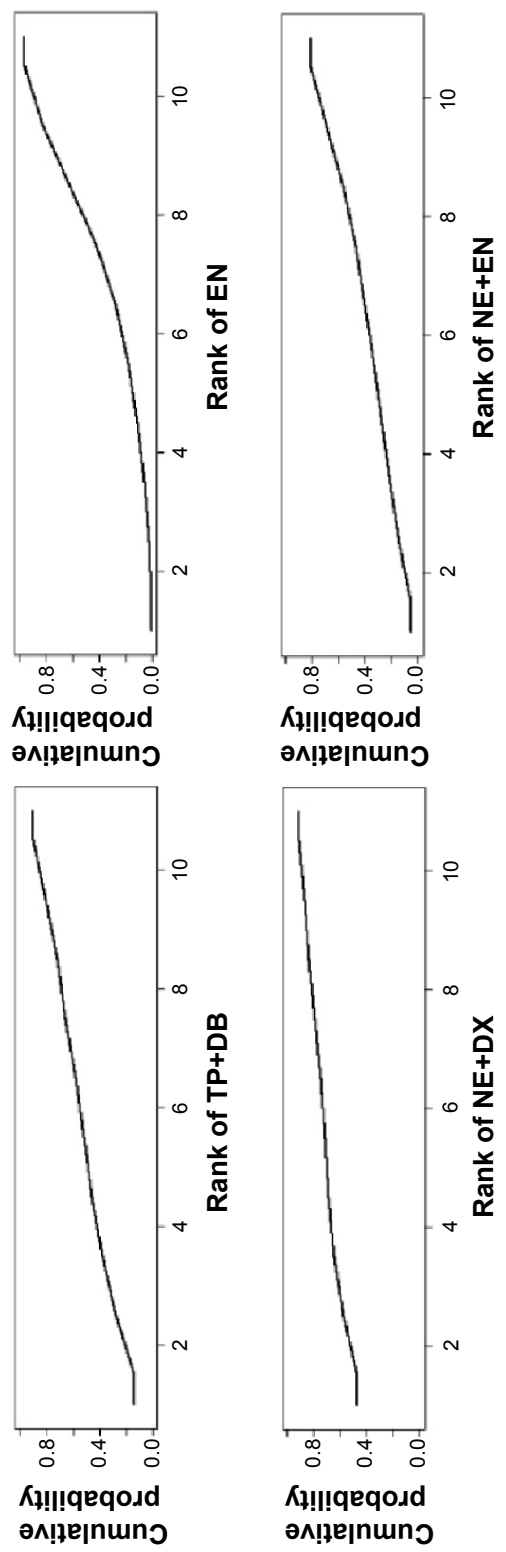

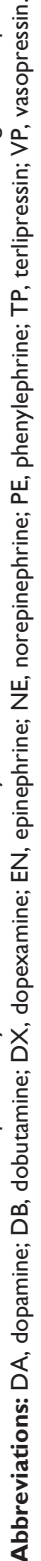

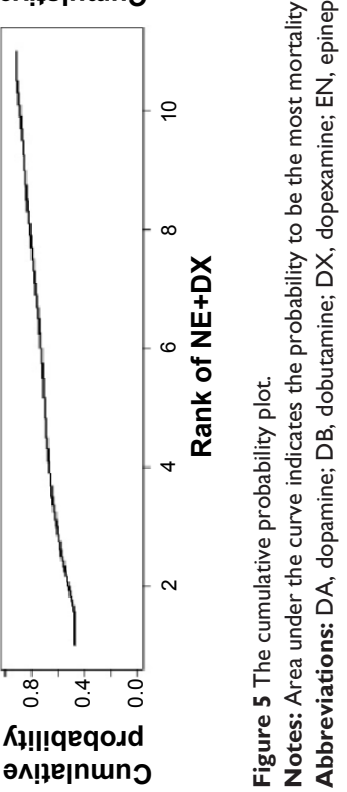


acd

afg

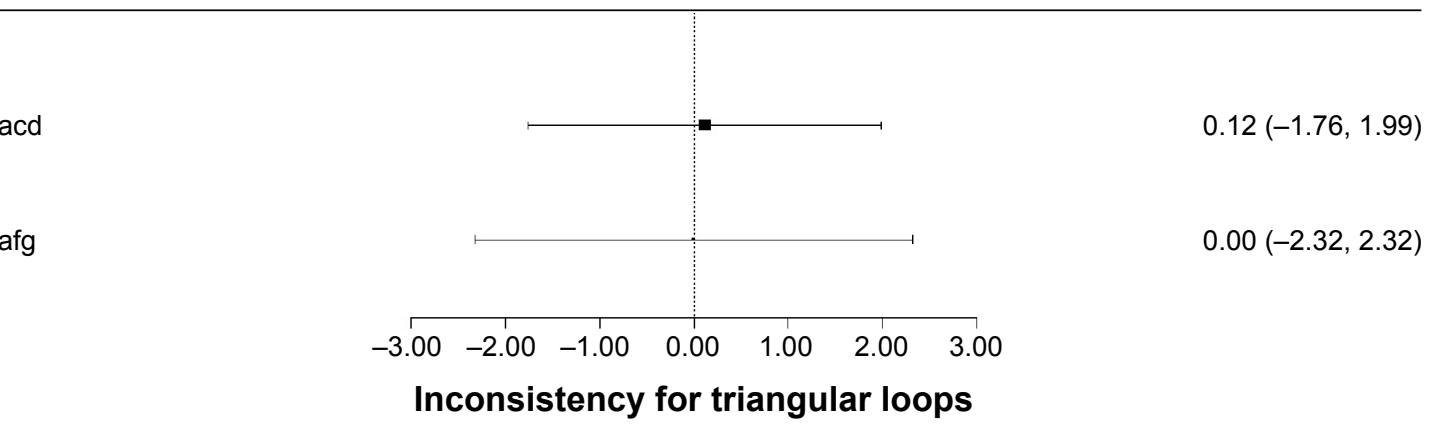

Figure 6 Inconsistency for triangular loops.

Notes: acd: norepinephrine, vasopressin, and terlipressin comparison closed loop; afg: norepinephrine, terlipressin + dobutamine, and terlipressin + norepinephrine comparison closed loop. The values are shown as mean (confidence interval of inconsistency estimate). The symbol $\mathbf{\square}$ indicates sample size.

to maintain adequate blood pressure and organ perfusion. However, different vasopressor agents and vasopressor combinations increase blood pressure through different mechanisms, leading to heterogeneity of physiological effects. ${ }^{37}$ $\mathrm{NE}$ is the first-line vasopressor agent used to treat septic shock (grade $1 \mathrm{~B})^{5}$ and is associated with lower mortality compared to DA..$^{6,7}$ Although the typical order for the addition of vasopressor agents is NE, epinephrine, VP, DA, and $\mathrm{PE},{ }^{38}$ the supporting evidence for this order is limited except for the superiority of NE over DA in terms of mortality. ${ }^{6,7}$ NE supplemented with EN is the second choice in treating septic shock (grade 2B)..$^{5}$ In this meta-analysis, only one study reported NE+EN vs NE+DB. ${ }^{11}$ The rank of probability of mortality revealed that NE+EN had lower risk than NE. VP is neither recommended nor suggested (grade UG) but can be added to NE with the intent of either raising MAP or decreasing NE dosage. ${ }^{5,38} \mathrm{PE}$, which is used to stimulate purely $\alpha-1$ receptors, is recommended when cardiac output is known to be high and the target blood pressure is not achieved (grade 1C). ${ }^{5}$ No significant difference between PE and other vasopressor agents or vasopressor combinations was found. Similar results were also found in the comparison between other vasopressor agents or vasopressor combinations. Recently, a trial compared the vasopressor effects of NE+DB and NE+EN on the cardiovascular support of patients with septic shock. ${ }^{11}$ To better evaluate any mortality benefit from the initial vasopressor used, we also compared vasopressor combinations of $\mathrm{NE}+\mathrm{DB}, \mathrm{TP}+\mathrm{NE}, \mathrm{TP}+\mathrm{DB}, \mathrm{NE}+\mathrm{EN}$, and $\mathrm{NE}+\mathrm{DX}$. The results showed that the vasopressor combination NE+DB had the lowest probability of mortality, and this finding may be supported by the rapid normalization of both gastric-arterial difference ( $\mathrm{PCO}_{2}$ gap) and gastric intramucosal $\mathrm{pH} .{ }^{22}$ No other vasopressor combination is superior to another in both direct and indirect comparisons.

For cardiac adverse events and hemodynamic and metabolic parameters, we conducted only direct comparisons because the small number of studies failed to form an effective network analysis loop. Our direct meta-analysis revealed that cardiac adverse events, HR, and cardiac index were decreased and SVRI was increased on treatment with NE compared to the results of treatment with DA. These results support the notion that NE may have stronger $\alpha$-receptor effects, resulting in a greater increase in SVRI and blood pressure as compared to DA., ${ }^{439}$ Even though some studies favored $\mathrm{NE}$ as the more effective vasopressor agent to maintain adequate MAP during septic shock, no significant difference in terms of effect on MAP between these two vasopressor agents has ever been detected..$^{20,40}$ Overall, NE

Table 3 Direct comparison of different vasopressors on cardiac adverse events

\begin{tabular}{llllll}
\hline & $\begin{array}{l}\text { Number } \\
\text { of studies }\end{array}$ & $\begin{array}{l}\text { Number } \\
\text { of patients }\end{array}$ & OR $(\mathbf{9 5} \% \mathbf{C l})$ & $\begin{array}{l}\text { Heterogeneity } \boldsymbol{I}^{2} \\
(\boldsymbol{P} \text {-value })\end{array}$ & $\begin{array}{l}\text { Test for effect } \\
(\boldsymbol{P} \text {-value }\end{array}$ \\
\hline NE vs DA & $1^{34}$ & 252 & $0.15(0.05,0.43)$ & - & 0.0005 \\
NE vs VP & $3^{10,25,31}$ & 831 & $1.30(0.73,2.32)$ & $0 \%(0.48)$ & 0.38 \\
NE vs TP & $1^{31}$ & 30 & $12.13(0.59,248.49)$ & - & 0.11 \\
NE vs PE & $1^{9}$ & 32 & $0.47(0.04,5.73)$ & - & 0.55 \\
TP+NE vs TP+DB & $1^{27}$ & 330 & $0.88(0.53,1.45)$ & - & 0.61 \\
TP+DB vs EN & $\mathrm{I}^{11}$ & 60 & $0.66(0.18,2.36)$ & - & 0.52 \\
\hline
\end{tabular}

Note: a Fixed-effect model.

Abbreviations: $\mathrm{Cl}$, confidence interval; DA, dopamine; DB, dobutamine; EN, epinephrine; NE, norepinephrine; PE, phenylephrine; TP, terlipressin; VP, vasopressin; vs, versus. 
Table 4 Direct comparison of different vasopressors on hemodynamic and metabolic parameters

\begin{tabular}{|c|c|c|c|c|c|}
\hline & $\begin{array}{l}\text { Number } \\
\text { of studies }\end{array}$ & $\begin{array}{l}\text { Number } \\
\text { of patients }\end{array}$ & SMD IV (95\% CI) & $\begin{array}{l}\text { Heterogeneity } I^{2} \\
(P \text {-value })\end{array}$ & $\begin{array}{l}\text { Test for effect } \\
\text { (P-value) }\end{array}$ \\
\hline \multicolumn{6}{|l|}{ NE vs DA } \\
\hline$H R$ & $4^{18-20,26}$ & 105 & $-2.10(-3.95,-0.25)$ & $91 \%(<0.0001)$ & $0.03^{\mathrm{a}}$ \\
\hline MAP & $3^{18-20}$ & 55 & $0.64(-1.09,2.38)$ & $87 \%(0.0004)$ & $0.47^{\mathrm{a}}$ \\
\hline Cardiac index & $4^{18-20,26}$ & 105 & $-0.73(-1.14,-0.03)$ & $43 \%(0.15)$ & $0.004^{b}$ \\
\hline SVRI & $4^{18-20,26}$ & 105 & $1.03(0.61,1.45)$ & $26 \%(0.25)$ & $<0.000 \mathrm{I}^{\mathrm{b}}$ \\
\hline $\mathrm{DO}_{2}$ & $4^{18-20,26}$ & 105 & $-0.54(-1.50,0.42)$ & $79 \%(0.003)$ & $0.27^{\mathrm{a}}$ \\
\hline $\mathrm{VO}_{2}$ & $4^{18-20,26}$ & 105 & $-0.49(-1.37,0.39)$ & $75 \%(0.008)$ & $0.27^{\mathrm{a}}$ \\
\hline Lactate & $3^{18-20}$ & 55 & $0.01(-0.53,0.56)$ & $23 \%(0.27)$ & $0.96^{\mathrm{b}}$ \\
\hline \multicolumn{6}{|l|}{ NE vs VP } \\
\hline $\mathrm{HR}$ & $3^{10,25,31}$ & 831 & $0.21(0.07,0.34)$ & $0 \%(0.96)$ & $0.003^{b}$ \\
\hline MAP & $3^{10,25,31}$ & 831 & $-0.07(-0.21,0.07)$ & $0 \%(0.70)$ & $0.76^{\mathrm{b}}$ \\
\hline Cardiac index & $3^{25,30,31}$ & 294 & $-0.04(-0.26,0.19)$ & $0 \%(0.93)$ & $0.76^{\mathrm{b}}$ \\
\hline SVRI & $2^{25,31}$ & 53 & $0.15(-0.39,0.70)$ & $0 \%(0.91)$ & $0.58^{\mathrm{b}}$ \\
\hline $\mathrm{DO}_{2}$ & $2^{25,31}$ & 53 & $-0.06(-0.62,0.49)$ & $0 \%(0.42)$ & $0.82^{b}$ \\
\hline $\mathrm{VO}_{2}$ & $2^{25,31}$ & 53 & $0.03(-0.52,0.59)$ & $0 \%(0.44)$ & $0.9 I^{\mathrm{b}}$ \\
\hline Lactate & $2^{25,31}$ & 53 & $0.25(-0.31,0.80)$ & $0 \%(0.95)$ & $0.38^{\mathrm{b}}$ \\
\hline \multicolumn{6}{|l|}{$\mathrm{NE}+\mathrm{DB}$ vs $\mathrm{EN}$} \\
\hline$H R$ & $2^{21,22}$ & 52 & $0.33(-0.22,0.89)$ & $49 \%(0.16)$ & $0.24^{b}$ \\
\hline MAP & $2^{21,22}$ & 52 & $-0.24(-0.78,0.3 \mathrm{I})$ & $0 \%(0.99)$ & $0.90^{\mathrm{b}}$ \\
\hline Cardiac index & $2^{21,22}$ & 52 & $-0.04(-0.59,0.5 \mathrm{I})$ & $48 \%(0.17)$ & $0.90^{\mathrm{b}}$ \\
\hline MPAP & $2^{21,22}$ & 52 & $-0.09(-0.63,0.45)$ & $0 \%(0.7 I)$ & $0.75^{b}$ \\
\hline $\mathrm{DO}_{2}$ & $2^{21,22}$ & 52 & $-0.19(-0.74,0.36)$ & $47 \%(0.17)$ & $0.50^{\mathrm{b}}$ \\
\hline $\mathrm{VO}_{2}$ & $2^{21,22}$ & 52 & $-0.13(-0.67,0.42)$ & $0 \%(0.4 I)$ & $0.65^{\mathrm{b}}$ \\
\hline Lactate & $2^{21,22}$ & 52 & $-0.11(-0.66,0.43)$ & $0 \%(0.59)$ & $0.69^{\mathrm{b}}$ \\
\hline
\end{tabular}

Notes: a Random-effects model; bfixed-effect model.

Abbreviations: $\mathrm{Cl}$, confidence interval; DA, dopamine; DB, dobutamine; $\mathrm{DO}_{2}$, oxygen delivery; EN, epinephrine; HR, heart rate; IV, inverse variance method; MAP, mean arterial pressure; MPAP, mean pulmonary arterial pressure; NE, norepinephrine; SMD, standardized mean difference; SVRI, systemic vascular resistance index; VO ${ }_{2}$, oxygen consumption; VP, vasopressin; vs, versus.

is probably more effective than DA in hemodynamic support for septic shock patients.

A previous trial reported that VP might increase SVRI and decrease cardiac index compared to baseline, while NE did not. ${ }^{25}$ Meta-analysis that included two trials failed to find any significant difference in cardiac adverse events as well as hemodynamic and metabolic parameters between NE and VP.

Statistically, with $80 \%$ power and two-sided alpha level of 0.04 , to detect a $15 \%$ relative difference in 28 -day mortality rate, at least 765 subjects in each group were needed..$^{35}$ In the present meta-analysis, only "NE vs VP" $(n=1,799)$ and "NE vs DA" $(n=1,408)$ comparisons had potentially adequate sample size.

\section{Limitations}

Our analysis has many limitations. First, only English language articles were included in this study, which may have affected the findings due to selection bias. Second, although
21 trials were included in this study, the actual sample size population in specific comparisons was small, and the risk of false attribution of positive effect from pooling small trials is well known. Moreover, differences in each RCT's inclusion criteria may have influenced the probability of mortality. Additionally, publication bias analysis could not be conducted. Hence, we do not think that these results constitute a reason to change clinical practice, but rather, they support the need for further investigations.

\section{Conclusion}

In terms of survival, NE may be superior to DA. Otherwise, there is insufficient evidence to suggest that any other vasopressor agent or vasopressor combination is superior to another. When compared to DA, NE is associated with decreased cardiac adverse events, HR, and cardiac index, as well as increased SVRI. The effects of vasopressor agents or vasopressor combinations on patients with septic shock require further investigation by larger-scale RCTs. 


\section{Disclosure}

The authors report no conflicts of interest in this work.

\section{References}

1. Levy MM, Dellinger RP, Townsend SR, et al. The surviving sepsis campaign: results of an international guideline-based performance improvement program targeting severe sepsis. Crit Care Med. 2010;38(2):367-374.

2. Angus DC, Linde-Zwirble WT, Lidicker J, Clermont G, Carcillo J, Pinsky MR. Epidemiology of severe sepsis in the United States: analysis of incidence, outcome, and associated costs of care. Crit Care Med. 2001;29(7):1303-1310.

3. Beck V, Chateau D, Bryson GL, et al; Cooperative Antimicrobial Therapy of Septic Shock (CATSS) Database Research Group. Timing of vasopressor initiation and mortality in septic shock: a cohort study. Crit Care. 2014;18(3):R97.

4. Sakr Y, Reinhart K, Vincent JL, et al. Does dopamine administration in shock influence outcome? Results of the sepsis occurrence in acutely ill patients (SOAP) study. Crit Care Med. 2006;34(3):589-597.

5. Dellinger RP, Levy MM, Rhodes A, et al; Surviving Sepsis Campaign Guidelines Committee including The Pediatric Subgroup. Surviving sepsis campaign: international guidelines for management of severe sepsis and septic shock: 2012. Crit Care Med. 2013;41(2): 580-637.

6. Vasu TS, Cavallazzi R, Hirani A, Kaplan G, Leiby B, Marik PE. Norepinephrine or dopamine for septic shock: systematic review of randomized clinical trials. J Intensive Care Med. 2012;27(3):172-178.

7. De Backer D, Aldecoa C, Njimi H, Vincent JL. Dopamine versus norepinephrine in the treatment of septic shock: a meta-analysis*. Crit Care Med. 2012;40(3):725-730.

8. Bartel B. Norepinephrine vs dopamine: new recommendations for initial vasopressor selection in septic shock. S D Med. 2014;67(5): 200-201.

9. Morelli A, Ertmer C, Rehberg S, et al. Phenylephrine versus norepinephrine for initial hemodynamic support of patients with septic shock: a randomized, controlled trial. Crit Care. 2008; 12(6):R143.

10. Russell JA, Walley KR, Singer J, et al; VASST Investigators. Vasopressin versus norepinephrine infusion in patients with septic shock. N Engl J Med. 2008;358(9):877-887.

11. Mahmoud K, Ammar A. Norepinephrine supplemented with dobutamine or epinephrine for the cardiovascular support of patients with septic shock. Indian J Crit Care Med. 2012;16(2):75-80.

12. Moher D, Liberati A, Tetzlaff J, Altman DG. Preferred reporting items for systematic reviews and meta-analyses: the PRISMA statement. Int J Surg. 2010;8(5):336-341.

13. Jadad AR, Moore RA, Carroll D, et al. Assessing the quality of reports of randomized clinical trials: is blinding necessary? Control Clin Trials. 1996;17(1):1-12.

14. Higgins JP, Thompson SG, Deeks JJ, Altman DG. Measuring inconsistency in meta-analyses. BMJ. 2003;327(7414):557-560.

15. Mills EJ, Ioannidis JP, Thorlund K, Schunemann HJ, Puhan MA, Guyatt GH. How to use an article reporting a multiple treatment comparison meta-analysis. JAMA. 2012;308(12):1246-1253.

16. Rochwerg B, Alhazzani W, Sindi A, et al; Fluids in Sepsis and Septic Shock Group. Fluid resuscitation in sepsis: a systematic review and network meta-analysis. Ann Intern Med. 2014;161(5):347-355.

17. Zhang C, Yan J, Sun F, Liu Q, Guo Y, Zeng X. Differentiation and handling of homogeneity in network meta-analysis. Chin J Evid Based Med. 2014;14(7):884-888.

18. Marik PE, Mohedin M. The contrasting effects of dopamine and norepinephrine on systemic and splanchnic oxygen utilization in hyperdynamic sepsis. JAMA. 1994;272(17):1354-1357.

19. Ruokonen E, Takala J, Kari A, Saxen H, Mertsola J, Hansen EJ. Regional blood flow and oxygen transport in septic shock. Crit Care Med. 1993; 21(9):1296-1303.
20. Martin C, Papazian L, Perrin G, Saux P, Gouin F. Norepinephrine or dopamine for the treatment of hyperdynamic septic shock? Chest. 1993; 103(6): 1826-1831.

21. Levy B, Bollaert PE, Charpentier C, et al. Comparison of norepinephrine and dobutamine to epinephrine for hemodynamics, lactate metabolism, and gastric tonometric variables in septic shock: a prospective, randomized study. Intensive Care Med. 1997;23(3):282-287.

22. Seguin P, Bellissant E, Le Tulzo Y, et al. Effects of epinephrine compared with the combination of dobutamine and norepinephrine on gastric perfusion in septic shock. Clin Pharmacol Ther. 2002;71(5): 381-388.

23. Albanese J, Leone M, Delmas A, Martin C. Terlipressin or norepinephrine in hyperdynamic septic shock: a prospective, randomized study. Crit Care Med. 2005;33(9):1897-1902.

24. Seguin P, Laviolle B, Guinet P, Morel I, Malledant Y, Bellissant E. Dopexamine and norepinephrine versus epinephrine on gastric perfusion in patients with septic shock: a randomized study [NCT00134212]. Crit Care. 2006;10(1):R32.

25. Lauzier F, Levy B, Lamarre P, Lesur O. Vasopressin or norepinephrine in early hyperdynamic septic shock: a randomized clinical trial. Intensive Care Med. 2006;32(11):1782-1789.

26. Mathur S, Dhunna R, Chakraborty A. Comparison of norepinephrine and dopamine in the management of septic shock using impedance cardiography. Indian J Crit Care Med. 2007;11(4):186-191.

27. Annane D, Vignon P, Renault A, et al; CATS Study Group. Norepinephrine plus dobutamine versus epinephrine alone for management of septic shock: a randomised trial. Lancet. 2007;370(9588):676-684.

28. Myburgh JA, Higgins A, Jovanovska A, Lipman J, Ramakrishnan N, Santamaria J. A comparison of epinephrine and norepinephrine in critically ill patients. Intensive Care Med. 2008;34(12):2226-2234.

29. Morelli A, Ertmer C, Lange M, et al. Effects of short-term simultaneous infusion of dobutamine and terlipressin in patients with septic shock: the DOBUPRESS study. Br J Anaesth. 2008;100(4):494-503.

30. Gordon AC, Wang N, Walley KR, Ashby D, Russell JA. The cardiopulmonary effects of vasopressin compared with norepinephrine in septic shock. Chest. 2012;142(3):593-605.

31. Morelli A, Ertmer C, Rehberg S, et al. Continuous terlipressin versus vasopressin infusion in septic shock (TERLIVAP): a randomized, controlled pilot study. Crit Care. 2009;13(4):R130.

32. Jain G, Singh DK. Comparison of phenylephrine and norepinephrine in the management of dopamine-resistant septic shock. Indian J Crit Care Med. 2010;14(1):29-34.

33. Gordon AC, Russell JA, Walley KR, et al. The effects of vasopressin on acute kidney injury in septic shock. Intensive Care Med. 2010; 36(1): 83-91.

34. Patel GP, Grahe JS, Sperry M, et al. Efficacy and safety of dopamine versus norepinephrine in the management of septic shock. Shock. 2010; 33(4):375-380.

35. De Backer D, Biston P, Devriendt J, et al; SOAP II Investigators. Comparison of dopamine and norepinephrine in the treatment of shock. N Engl J Med. 2010;362(9):779-789.

36. Bone RC, Balk RA, Cerra FB, et al; ACCP/SCCM Consensus Conference Committee. Definitions for sepsis and organ failure and guidelines for the use of innovative therapies in sepsis. The ACCP/SCCM Consensus Conference Committee. American College of Chest Physicians/Society of Critical Care Medicine. Chest. 1992;101(6):1644-1655.

37. Hollenberg SM. Inotrope and vasopressor therapy of septic shock. Crit Care Clin. 2009;25(4):781-802.

38. Arellano DL, Hanneman SK. Vasopressor weaning in patients with septic shock. Crit Care Nurs Clin North Am. 2014;26(3):413-425.

39. Bracco D. Pharmacologic support of the failing circulation: practice, education, evidence, and future directions. Crit Care Med. 2006;34(3): 890-892.

40. Reinhart K, Sakka SG, Meier-Hellmann A. Haemodynamic management of a patient with septic shock. Eur J Anaesthesiol. 2000;17(1):6-17. 
Therapeutics and Clinical Risk Management

Dovepress

\section{Publish your work in this journal}

Therapeutics and Clinical Risk Management is an international, peerreviewed journal of clinical therapeutics and risk management, focusing on concise rapid reporting of clinical studies in all therapeutic areas outcomes, safety, and programs for the effective, safe, and sustained use of medicines. This journal is indexed on PubMed Central, CAS,
EMBase, Scopus and the Elsevier Bibliographic databases. The manuscript management system is completely online and includes a very quick and fair peer-review system, which is all easy to use. Visit http://www.dovepress.com/testimonials.php to read real quotes from published authors.

Submit your manuscript here: http://www.dovepress.com/therapeutics-and-clinical-risk-management-journal 